\title{
Chronic functional constipation. Which supplementary fiber to choose?
}

\author{
Helga Verena L. Maffei*
}

$D_{i}$ etary fiber (DF) increases fecal weight by mechanisms that depend on the structure of its components and on the intricate relationship between its physico-chemical properties (water-holding capacity, solubility, particle size, degree of lignification, pentose concentrations, etc.) and the bacterial population of the colon. As the insoluble components of the fiber resist bacterial breakdown, they are eliminated intact and keep the retained water, generating high fecal weight. During the colonic transit this large bulk stimulates propulsive contractions and, transit time being shortened, there might be less water reabsorption, feces becoming wetter. In contrast, $90-100 \%$ of the soluble fibers (but just $30-80 \%$ of the insoluble) are fermented by the intestinal flora, liberating the retained water and producing shortchain fatty acids. These acids are absorbed, generating water absorption and electrolyte co-absorption, which together with the absorption of the liberated water tends to reduce fecal water content. However, fermentation is also a great stimulus for bacterial mass increase, which, making up around $50 \%$ of dry feces, contributes to fecal weight. There are indications that fermentation increases with prolonged fiber consumption, since the bacterial flora polysaccharidases are inducible. Summing up, the main characteristics required for good laxation are attributed to the insoluble fraction of fiber, the soluble fraction playing a contributory role, although it does fulfill other important metabolic functions. ${ }^{1,2}$ In addition, excess fermentation has undesirable clinical effects.

Variations occur depending on whether fibers are ingested pure, as in many experiments, or as ingredients in foods. For example, pure cellulose isolated from wood is less digestible than that of fruit and vegetable because it is highly crystallized and has a small surface area. Wheat bran, having highly lignified cell walls, ferments less than cabbage or apples,

* Full professor, Department of Pediatrics, School of Medicine of Botucatu, Universidade Estadual de São Paulo (UNESP), Botucatu, SP, Brazil. and is considered slowly fermentable, while fine bran is more digestible than coarse bran because of the greater exposed area. ${ }^{1,2}$

While there are few studies assessing the use of DF in the treatment of chronic constipation in infancy, work done with adults and animals has demonstrated that, indeed, supplements containing large amounts of insoluble fiber in general generate higher fecal weight than those with more soluble fiber and/or decrease colonic transit time.1,3-5 However, Chen et al. ${ }^{6}$ were recently unable to find differences in wet fecal weight of human volunteers receiving wheat or oat bran (apparently cooked) containing $95 \%$ or $50 \%$ of insoluble fiber. In their experiment fecal weight increased $4.8 \mathrm{~g}$ and $4.5 \mathrm{~g}$ per $\mathrm{g}$ of DF consumed, respectively, whereas in an extensive compilation by Cummings et al. ${ }^{1}$ values were $4.9 \mathrm{~g}$ (cooked wheat bran) and $3.4 \mathrm{~g}$ (oat bran). Different methods for measuring the fibers in the various studies may explain the divergent results. According to Chen et al. ${ }^{6}$ the two brans behaved similarly because the soluble fiber in oat bran stimulates bacterial growth in the proximal colon and then the more slowly fermentable insoluble fraction of this bran maintains the bacterial population during the rest of the transit through the colon. Such hypothesis is compatible with the negligible fecal weight increase when only soluble fiber is given. The rapid bacterial growth in the proximal colon would not be sustained because of the lack of an insoluble fraction and autolysis would consume most of the bacterial increase by the time excretion occurs, approximately 2 days later. ${ }^{6}$

In the above cited compilation, ${ }^{1}$ the increase in wet fecal weight varied depending on the ingested fiber, the lowest increment being with soluble fiber pectin, $1.2 \mathrm{~g}$ per $\mathrm{g}$ ingested gram, and the greatest being $7.2 \mathrm{~g}$, with uncooked wheat bran, with $76 \%$ insoluble fiber. Soy products increased fecal weight by just $2.5 \mathrm{~g}$ for each ingested gram, in accordance with the minor effects observed in clinical trials with soy polysaccharide. ${ }^{2,7}$ This product has traditionally been used for enteral nutrition because of its easy infusion 
via the probe, which led Silk to question whether processing to very small particles in order to obtain the low viscosity required for enteral diets, has increased digestibility and reduced water-holding capacity, both factors known to mitigate against stool bulking. ${ }^{2}$ Indeed, albeit soy polysaccharide contains between 75 and $90 \%$ insoluble material and, therefore, potentially being poorly fermentable, in vitro studies have demonstrated greater degrees of fermentation than might be expected. ${ }^{7}$

The paper by Freitas et al., in the current issue, ${ }^{8}$ also describes a lack of efficacy when soy polysaccharide was used in children with chronic functional constipation and is an excellent example of experimental investigation based on clinical observation. Thus, the authors attempted to test whether the lack of efficacy observed in their clinical trial, compared with soy formula without DF, would be reproduced experimentally. However, contrary to what was observed clinically, in rats, a diet containing soy polysaccharide proved itself effective, as did the standard diet containing cellulose. Furthermore, the dry weight was significantly lower and fecal moisture significantly higher for rats on soy polysaccharide than for those on cellulose, with the higher percentage of fecal moisture, at all moments ( $61 \%$ vs. $36 \%$ ), attributed to greater fermentation. ${ }^{8}$ In the paper by McIntyre et al., ${ }^{9}$ however, percentage moisture was similar for rats on diets containing guar gum or wheat bran, even though their percentages of soluble fiber vary greatly $(85 \%$ vs. $24 \%$ ). Fecal moisture in humans, in addition to always being much higher than in rats, also varies little, between 68 and $82 \%$ in almost all studies (including those with cellulose), without differences between those with supplemental DF and those with small amounts of DF. ${ }^{1}$ It is questionable, therefore, to what extent data on fecal moisture percentage in rats can be transposed to humans.

Cellulose is considered appropriate for good laxation because it predominantly contains insoluble fiber, for which reason it is used in animal feeds. ${ }^{5,9}$ In contrast, as mentioned earlier, scientific literature has questioned the efficacy of soy polysaccharides. ${ }^{2,7}$ Therefore, in our view, the results of the prior clinical trial were not unexpected, but the experimental results from the article in question ${ }^{8}$ are, to a certain extent, surprising. It would be interesting to confirm the data, taking the ingested volume into account, as possible differences in the diets characteristics such as taste, smell, viscosity etc. may lead to differences in the ingested volume, and consequently the amount of ingested DF, ingested. Indeed, the same research team observed, in an excellent previous experiment, significantly greater ingestion of the diet containing cellulose than of the diet without DF. ${ }^{10}$ In addition, in that experiment ${ }^{10}$ exactly double the quantity of DF ( $100 \mathrm{~g}$ of cellulose per $\mathrm{kg}$ of diet), than in the experiment by Freitas et al., ${ }^{8}$ was offered, generating a much higher fecal weight (10.7 vs. $5.2 \mathrm{~g})$. According to Catani et al., $1050 \mathrm{~g}$ of cellulose corresponds to $12.5 \mathrm{~g}$ of fiber per $1,000 \mathrm{kcal}$, which would be the recommended intake for children. However, taking into account the fecal characteristics of rats, it could be asked whether the higher DF proportion would be desirable. As in a large proportion of experimental work with animals $100 \mathrm{~g}$ is offered, 5,9 the question arises of what influence the reduced quantity might have had on the results found by Freitas et al. ${ }^{8}$

The authors could also reward us with the reverse path, investigating, in children, whether supplementation with products containing large quantities of cellulose is more effective for dry fecal weight than those with soy polysaccharide and if this has a beneficial effect on chronic constipation. It would also be interesting to test the effects of the different supplements on rats previously fed a DF-free diet, to better simulate the clinical condition of constipated children.

While these methodological questions are being discussed and new products well accepted by the patients are looked for, it is up to clinicians, working within established knowledge, to find ways of making constipated children accept a diet containing whole grains, fruit with peel and bagasse, vegetables and pulses, in addition to performing necessary interventions including supplementation with fibers. Wheat bran, because of its high level of insoluble fiber (lignin, cellulose and non-cellulosic polysaccharides) and high pentose levels, appears to be the ideal fiber, which has been confirmed in several studies of constipated adults. ${ }^{3}$ The great problem, particularly in our country, is its acceptance over the long-term, which gives rise to the salutary search for other products that could act as a substitute and be better accepted by the public. It is within this context that we insert the laudable attempt to treat constipated children with a commercial product containing soy polysaccharide. 8

\section{References}

1. Cummings $\mathrm{JH}$. The effect of dietary fiber on fecal weight and composition. In: Spiller GA, editor. CRC Handbook of dietary fiber in human nutrition. Boca Raton, FL: CRC Press; 2001. p. 183-252.

2. Silk DBA. Fibre and enteral nutrition. Gut. 1989;30:246-64.

3. Tomlin J, Read NW. Comparison of the effects on colonic function caused by feeding rice bran and wheat bran. Eur J Clin Nutr. 1988;42:857-61.

4. Meier R, Beglinger C, Schneider H, Rowedder A, Gyr K. Effect of a liquid diet with and without soluble fiber supplementation on intestinal transit and cholecystokinin release in volunteers. J Parenter Enteral Nutr. 1993;17:231-5.

5. Nyman M, Asp NG. Fermentation of dietary fibre components in the rat intestinal tract. Br J Nutr. 1982;47:357-66.

6. Chen HL, Haack VS, Janecky CW, Vollendorf NW, Marlett JA. Mechanisms by which wheat bran and oat bran increase stool weight in humans. Am J Clin Nutr. 1998;68:711-9.

7. Kapadia SA, Raimundo AH, Grimble GK, Aimer P, Silk DB. Influence of three different fiber-supplemented enteral diets on bowel function and short-chain fatty acid production. J Parenter Enteral Nutr. 1995;19:63-8.

8. Freitas KC, Motta MEFA, Amâncio OMS, Fagundes-Neto U, Morais MB. Efeito da fibra do polissacarídeo de soja no peso e na umidade das fezes de ratos em fase de crescimento. J Pediatr (Rio J). 2004;80:183-8.

9. McIntyre A, Young GP, Taranto PRG, Gibson PR, Ward PB. Different fibers have different regional effects on luminal contents of rat colon. Gastroenterology. 1991;101:1274-81.

10. Catani M, Amâncio OMS, Fagundes-Neto U, Morais MB. Dietary cellulose has no effect on the regeneration of hemoglobin in growing rats with iron deficiency anemia. Braz J Med Biol Res. 2003;36:693-7. 